\title{
Rancang Bangun Sistem Proteksi Kebakaran Menggunakan Smoke dan Heat Detector
}

\author{
Abdul Zain ${ }^{1, a}$ \\ ${ }^{1}$ Sekolah Tinggi Teknologi Bontang Program Studi Teknik Elektro \\ J1. Ir. H. Juanda, No. 73 Rt. 36, Tanjung Laut, Bontang \\ a jainbtg2013@gmail.com
}

\begin{abstract}
The growth of rapid development in the big cities but without well planning in terms of fire prevention and the things that can cause a fire, for example electrical installations and gas that can either lead to frequent fires in the residential homes. The aim of the study is to prevent fires by detecting the presence of smoke and excessive heat around the house and protect the occurrence of fires that have wide impacts. The outcome of the fire protection design using smoke and heat detector based on microcontroller is to detect both smoke and heat hazards. If there is a danger of smoke or heat, then the system will provide a warning alarm, provide the path to the door emergency evacuation, and provide protection to extinguish the fire before the fire was enlarged.
\end{abstract}

Key words: Design, detection, protection, smoke and heat.

\begin{abstract}
Abstrak-Pertumbuhan pembangunan yang pesat di kota-kota besar namun tidak disertai perencanaan dalam hal pencegahan bahaya kebakaran dan hal-hal yang dapat menyebabkan kebakaran misalnya instalasi listrik dan gas yang baik dapat menyebabkan seringnya terjadi kebakaran di pemukiman. Tujuan dari penelitian yakni mencegah terjadinya kebakaran dengan mendeteksi adanya asap dan panas yang berlebihan di sekitar rumah dan melindungi terjadinya kebakaran yang berdampak luas. Hasil rancang bangun proteksi kebakaran menggunakan smoke dan heat detector berbasis mikrokontroler akan mendeteksi adanya bahaya asap dan panas. Apabila ada bahaya asap atau panas, maka sistem akan memberikan peringatan berupa alarm, memberikan jalur evakuasi menuju pintu emergency, dan memberikan proteksi dengan memadamkan api tersebut sebelum api itu membesar.
\end{abstract}

Kata Kunci : Rancang bangun, deteksi, proteksi, smoke and heat.

\section{Pendahuluan}

Perkembangan struktur bangunan yang semakin kompleks dan penggunaan bangunan yang semakin beragam serta tuntutan keselamatan yang semakin tinggi membuat pihak pemilik bangunan harus mulai memikirkan tingkat keselamatan bangunan dari bahaya kebakaran. Beberapa kejadian kebakaran pada bangunan mestinya menjadi pelajaran penting dalam penyiapan sistem keselamatan. Pada saat terjadi kebakaran, ada empat hal yang perlu diperhatikan berkaitan dengan bahaya kebakaran, yaitu penghuni bangunan (manusia), isi bangunan (harta), struktur bangunan dan bangunan lainnya yang berada disebelah bangunan itu sendiri.

Berdasarkan data dari Badan Nasional Penanggulangan Bencana (BNPB), terdapat 399 kebakaran pemukiman di tahun 2013, sedangkan ditahun berikutnya sampai tanggal 6 Oktober, pemukiman yang terbakar sudah terjadi sebanyak 406 kebakaran (BNPB, 2014). Berdasarkan data tersebut terjadi peningkatan frekuensi kebakaran pemukiman dari tahun 2013 ke tahun 2014.Keselamatan adalah pertimbangan utama ketika kebakaran terjadi pada sebuah bangunan.Berdasarkan data dari BNPB mengenai kebakaran pemukiman yang terjadi di Indonesia dari tahun 2013 ada 79 korban jiwa meninggal dunia, 347 jiwa terluka, 11284 jiwa harus mengungsi karena kehilangan tempat tinggal mereka, dan 8706 jiwa mendapat dampak secara tidak langsung seperti menderita penyakit ISPA.Kerugian materi yang sudah terdata sekitar 10606 bangunan dan 36 unit kendaraan bermotor terbakar [1].

Untuk menekan angka kebakaran dan jumlah korban yang terus meningkat, perlu dilakukan suatu tindakan yang mengutamakan keselamatan. Peringatan dini terhadap tanda-tanda kebakaran merupakan salah satu solusi dari bahaya kebakaran. Tanda-tanda kebakaran dapat dideteksi karena kebakaran selalu mengeluarkan asap dan panas. Tindakan itu akan lebih cepat dilakukan jika terdapat pendeteksi dan proteksi kebakaran secara otomatis untuk mengurangi dampak 
kebakaran. Selain pendeteksi dan proteksi perlu ditambahkan juga sebuah evakuasi yang dapat membantu penghuni saat terjadi kebakaran. Oleh karena itu diperlukan suatu sistem yang dapat mengurangi kemungkinan terjadinya dampak kebakaran dengan memanfaatkan smoke dan heat detector sebagai pendeteksi.

\section{Dasar Teori}

\subsection{Mikrokontroler}

Mikrokontroler adalah piranti elektronik berupa IC (Integrated Circuit) yang memiliki kemampuan manipulasi data (informasi) berdasarkan suatu urutan instruksi (program) yang dibuat oleh programmer.Mikrokontroler merupakan contoh suatu sistem komputer sederhana yang terdapat hanya dalam satu chip [2].

Mikrokontroler ATMega32 menggunakan arsitektur Harvard yang memisahkan memori program dari memori data, baik bus alamat maupun bus data, sehingga pengaksesan program dan data dapat dilakukan secara bersamaan (concurrent). Secara garis besar mikrokontroler ATMega32 terdiri dari:

1) Arsitektur RISC dengan throughput mencapai 16 MIPS pada frekuensi 16Mhz.

2) Memiliki kapasitas Flash memori 32Kbyte, EEPROM 1Kbyte, dan SRAM 2Kbyte.

3) Saluran I/O 32 buah, yaitu Port A, Port B, Port C, dan Port D.

4) CPU yang terdiri dari 32 buah register.

5) User interupsi internal dan eksternal.

6) Port antarmuka SPI dan Port USART sebagai komunikasi serial.

7) Fitur Peripheral

8) Dua buah 8-bit timer/counter dengan prescaler terpisah dan mode compare.

9) Satu buah 16-bit timer/counter dengan prescaler terpisah, mode compare, dan mode capture.

10) Satu buah 16-bit timer/counter dengan prescaler terpisah, mode compare, dan mode capture.

11) Real timecounter dengan osilator tersendiri

12) Empat kanal PWM dan Antarmuka komparator analog.

13) Byte-oriented Two-wire Serial Interface

14) Watchdog timer dengan osilator internal.

\subsection{Voltage Devider}

Resistor yang sering disebut hambatan, tahanan mempunyai fungsi sebagai penghambat arus, pembagi arus, dan pembagi tegangan.Resistor jika disusun seri berfungsi sebagai pembagi tegangan.Pembagi teganganatau voltage divideradalah sebuah rangkaian elektronika yang digunakan untuk menghasilkan tegangan keluaran yang nilainya berasal dari pembagian nilai tegangan masukan.Rangkaian pembagi tegangan pada umumnya bisa dibuat dengan 2 buah resistor [3].

\subsection{Smoke detector}

Smokedetector adalah sensor yang digunakan untuk memproteksi secara dini ruangan dari kebakaran dengan mendeteksi asap yang keluar sebelum api membesar. Jenis smokedetector ada 2 yaitu OpticalSmokedetector dan IonizationSmoke detector. OpticalSmokedetector adalah sensor cahaya. Komponen sensor cahaya adalah sumber cahaya (Light Emitting Dioda) , lensa, dan penerima fotolistrik. Photoelectric sensor akan terus menerus memancarkan cahaya ke sebuah dioda penerima. Apabila kekuatan cahaya berkurang sampai nilai tertentu maka photoelectricdetectorakan mendeteksi adanya asap.

Ionizationsmokedetector menggunakan metode ionization chamber.Smoke detector ini terdiri atas dua plat yang bermuatan listrik dan terdapat bahan radioaktif di antara plat positif dan negatif. Tumbukan antar partikel tersebut akan menyebabkan adanya ion positif dan negatif yang akan tertarik ke dua plat dan membentuk arus dengan nilai tertentu. Apabila ada asap yang masuk maka ion akan bereaksi dengan asap dan sensor pun bekerja [4].

\subsection{Heat Detector}

Heatdetector adalah pendeteksi kenaikan panas. Jenis yang digunakan bermacam-macam seperti Bimetal switch, Thermocouple, RTD (Resistant Temperature Detector), PTC (positive temperature coefficient), NTC (Negative temperature coefficient), dan masih banyak sensor lainnya. Heat detector banyak digunakan karena detector ini bekerja berdasarkan kenaikan temperatur secara cepat di satu ruangan kendati masih berupa hembusan panas. Umumnya pada titik $55^{\circ} \mathrm{C}-63^{\circ} \mathrm{C}$ sensor ini sudah aktif dan membunyikan alarmbell 
kebakaran..Prinsip kerja Heat detector sebenarnya hanya saklar bi-metal biasa, saklar bi-metalakan berubah kontak saat mendeteksi panas.

\subsection{Switch}

Switch adalah suatu komponen yang berfungsi untuk memutus atau menghubungkan arus listrik, switch didalam firealarm ini berfungsi untukManual Switch, Bypass Switch, Reset Switch, Hold Switch, Mute Switch.

\subsection{LCD (Liquid Cristal Display)}

LCD adalah lapisan dari campuran organik antara lapisan kaca bening dengan elektroda transparan indium oksida dalam bentuk tampilan seven-segment dan lapisan elektroda pada kaca belakang. Ketika elektroda diaktifkan dengan medan listrik (tegangan), molekul organik yang panjang dan silindris menyesuaikan diri dengan elektroda dari segmen. Lapisan sandwich memiliki polarizer cahaya vertikal depan dan polarizer cahaya horisontal belakang yang diikuti dengan lapisan reflektor. Cahaya yang dipantulkan tidak dapat melewati molekul-molekul yang telah menyesuaikan diri dan segmen yang diaktifkan terlihat menjadi gelap dan membentuk karakter data yang ingin ditampilkan [5].

\subsection{Solenoid Valve}

Solenoid valve merupakan salah satu alat atau komponen kontrol yang salah satu kegunaannya yaitu untuk menggerakan tabung silinder, Solenoid Valve merupakan katup listrik yang mempunyai koil sebagai penggeraknya yang mana ketika koil mendapat supply tegangan maka koil tersebut akan berubah menjadi medan magnet sehingga menggerakan piston pada bagian dalamnya ketika piston berpindah posisi maka pada lubang keluaran A atau B dari solenod valve akan keluar udara yang berasal dari $\mathrm{P}$ atau supply, pada umumnya solenoid valve mempunyai tegangan kerja 100/200 VAC namun ada juga yang mempunyai tegangan kerja DC [6].

\subsection{Buzzer}

Buzzer adalah sebuah komponen elektronika yang berfungsi untuk mengubah getaran listrik menjadi getaran suara. Pada dasarnya prinsip kerja buzzer hampir sama dengan loud speaker, jadi buzzer juga terdiri dari kumparan yang terpasang pada diafragma dan kemudian kumparan tersebut dialiri arus sehingga menjadi elektromagnet, kumparan tadi akan tertarik ke dalam atau keluar, tergantung dari arah arus dan polaritas magnetnya, karena kumparan dipasang pada diafragma maka setiap gerakan kumparan akan menggerakkan diafragma secara bolak-balik sehingga membuat udara bergetar yang akan menghasilkan suara [3].

\subsection{Lampu Evakuasi}

Lampu evakuasi yang dipakai pada sistem ini adalah LED yang mempunyai daya kecil, dimana LED tersebut dipasang secara seri dan parallel.LED atau kepanjangannya Light Emitting Dioda adalah suatu lampu indikator dalam perangkat elektronika yang biasanya memiliki fungsi untuk menunjukkan status dari perangkat elektronika tersebut, LED juga berfungsi sebagai lampu hiasan yang jika disusun sedemikian rupa sesuai kebutuhan.Lampu LED terbuat dari plastik dan dioda semikonduktor yang dapat menyala apabila dialiri tegangan listrik rendah (sekitar 1.5 VDC).Bermacammacam warna dan bentuk dari lampu LED, disesuaikan dengan kebutuhan dan fungsinya.LED merupakan jenis dioda semikonduktor yang dapat mengeluarkan energi cahaya ketika diberikan tegangan [7].

\subsection{Power Supply}

Catu daya atau power supply merupakan suatu rangkaian elektronik yang mengubah arus listrik bolakbalik menjadi arus listrik searah. Catu daya menjadi bagian yang penting dalam elektonika yang berfungsi sebagai sumber tenaga listrik misalnya pada baterai atau accu.Catu daya (Power Supply) juga dapat digunakan sebagai perangkat yang memasok listrik energi untuk satu atau lebih beban listrik. 


\section{Metodologi Penelitian}

\subsection{Perancangan Perangkat Keras}

Perancangan perangkat keras (hardware) meliputi perancangan miniatur proteksi kebakaran, perancangan rangkaian sistem minimum mikrokontroler, rangkaian input atau sensor, perancangan rangkaian output, perancangan rangkaian kontrol.

Rangkaian sistem minimum mikrokontroler adalah sistem elektronika yang terdiri dari komponenkomponen dasar yang dibutuhkan oleh suatu mikrokontroler untuk dapat berfungsi dengan baik.Pada umumnya, suatu mikrokontoler membutuhkan dua elemen (selain power supply) yaitu Kristal Oscillator (XTAL) dan Rangkaian RESET. Pada sistem minimum AVR khususnya ATMega32 terdapat elemen tambahan (optional), yaitu rangkaian pengendalian ADC: $A G N D$ (= GND ADC), AVCC (VCC ADC), dan AREF (Tegangan Referensi $A D C$ ). Untuk mengunduh (download) program ke mikrokontroler ditambahkan konektor ISP.

Untuk menampilkan karakter LCD diperlukan sebuah rangkaian driver, dan ditambah sebuah lampu yang menjadikan karakter tersebut dapat dibaca dengan jelas, untuk membuat kontras LCD lebih jelas perlu diinput tegangan kekaki VEE.Kontras tersebut dapat diatur dengan memanfaatkan sebuah rangkaian voltage devider menggunakan sebuah potensiometer.

Smoke detector menggunakan smoke detector jenis HOCHIKI, sensor tersebut membutuhkan tegangan 8 VDC sampai 32 VDC.Smoke detector biasanya dipasang pada plafon yang memungkinkan terjadinya kerusakan pada kabel, kerusakan pada kabel biasanya terjadi oleh gigitan-gigitan binatang seperti tikus dan serangga, untuk memastikan kabel tersebut tidak rusak diperlukan line monitoring, hanya dengan menambahkan sebuah resistor pada ujung kabel.Tegangan pada smokeakan mengalami fluktuasi tergantung intensitas asap yang dibaca, perubahan tegangan tersebutlah yang dimanfaatkan oleh mikrokontroler. Perubahan tegangan yang besar yaitu dari 8 VDC sampai 32 VDC akan menyebabkan mikrokontroler rusak, oleh karena itu tegangan tersebut perlu dikonversi menjadi 0-5 VDC agar dapat dibaca oleh rangkaian ADC mikrokontroler, agar proteksi lebih safety maka sensor ini dirancang dengan sistem latching artinya apabila sensor bekerja aktif) maka sensor akan tetap aktif sebelum direset catudayanya.

Heat detector yang digunakan adalah bimetal switch, untuk membaca perubahan kontak pada switch diperlukan sebuah voltage dvider, sedangkan untuk proteksi kabel (line monitoring) digunakan sebuah resistor yang dipasang diujung kabel, rangkaian ini juga digunakan untuk switch manual release dan bypass switch.

Alat pendeteksi kebakaran akan bekerja secara terus menerus, untuk itu diperlukan listrik yang terus menerus. Untuk menghindari adanya kegagalan supply listrik 220 VAC diperlukan sebuah catudaya cadangan berupa battery DC. Battery tersebut harus dipastikan bekerja saat dibutuhkan, agar tegangan battery mencukupi saat dibutuhkan perlu ditambahkan rangkaian pengisi battery.Rangkaian ini dirancang otomatis agar battery tersebut awet.

Sistem proteksi ini mempunyai output buzzer, solenoid valve dan relay contact untuk mematikan AC. Untuk mengaktifkan output tersebut mikrokontroler perlu tambahan rangkaian driver relay, dimana relay tersebut akan aktif apabila mikrokontroler mengirim sinyal high ke relay.

Sistem proteksi ini akan membuka pintu emergency exit secara otomatis. Untuk mengaktifkan output tersebut mikrokontroler perlu tambahan rangkaian drivermotor, prinsip rangkaian ini adalah mengubah arah putaran motor, apabila mikrokontroler mengirim sinyal highmotorakan berputar searah jarum jam. Sedangkan jika mikrokontroler mengirim sinyal low maka motor akan berputar berlawan jarum jam, untuk mencegah motor tersebut berputar terus ditambahkan sebuah limit switch pada posisi pintu menutup penuh, dan sebuah limit switch pada pintu posisi membuka penuh, limit switch tersebut akan memutus arus pada saat pintu membuka atau menutup penuh.

Lampu evakuasi merupakan susunan beberapa LED yang disusun seri dan parallel, LED tersebut akan hidup mati seperti rangkaian flip-flop, untuk mendriveLED tersebut diperlukan sebuah saklar elektronik berupa transistor NPN.

Solenoid valve merupakan suatu kerangan yang digerakan oleh energi listrik.Valve yang digunakan 
adalah valve jenis 2-way dengan kondisi normal tutupan atau NC, dimana inputnya dihubungkan dengan media pemadam (air bertekanan) sedangkan outputnya dihubungkan ke spray untuk memadamkan api.

Power supply atau catudaya merupakan bagian paling penting didalam sistem proteksi ini. Sistem proteksi ini membutuhkan beberapa tegangan diantaranya 15 VDC untuk solenoid valve, 12 VDC untuk sensor, Fan, dan lampu evakuasi, serta 5 VDC untuk sistem minimum ATMega32, dan relay.

\subsection{Perancangan Perangkat Lunak}

Sistem perangkat keras (hardware) yang dirancang menggunakan mikrokontroler sebagai pengendali utamanya tidak akan dapat bekerja jika tidak disertai dengan perangkat lunak (software) yang dirancang sebagai pengontrol sistem secara keseluruhan. Perangkat lunak ini berfungsi sebagai pengontrol dan penghubung yang mengatur langkah-langkah yang harus dilakukan mikrokontroler pada keseluruhan sistem, sehingga dapat ditentukan arah kendali atau proses dari sistem yang dibuat. Perangkat lunak ini dirancang menggunakan bahasa C. Data yang diproses pada sistem ini merupakan data digital yang diolah oleh mikrokontroler menggunakan sintask software terprogram melalui software CodeVision AVR dan Extreme Burner sebagai downloader USB ISP.

Sistem proteksi kebakaran ini memiliki 6 inputan perintah yang terdiri dari 2 buah dari smoke detector, 2 buah dari heatdetector, sebuah Manual release switch dan sebuah Bypass switch. Masing-masing inputan tersebut mempunyai tiga buah kondisi yaitu Normal, Fault, dan Aktif. Kondisi input normal adalah dimana input dalam kondisi normal, Faultadalah kondisi input error dikarenakan line monitoring tidak bekerja atau kabel sensor putus, sedangkan Aktif adalah input dalam kondisi aktif. Penggabungan antara enam buah input dengan tiga kondisi menghasilkan alarm sebanyak $3^{6}=729$ jenis alarm, ditambah dua buah alarm battery fault dan AC $220 \mathrm{~V}$ fault, sehingga total alarm yang mungkin terjadi sebanyak 731 jenis alarm. Untuk menentukan jenis-jenis alarm yang mungkin terjadi dapat dicari dengan menggunakan Cartesian product.Salah satu software yang bisa digunakan untuk Cartesian product adalah Microsoft Excel dilengkapi
DigDB. Secara umum alarm dari sistem proteksi ini terdiri dari dua jenis alarm yaitu AlarmAlertberfungsi sebagai pre-alarm sebelum terjadinya kebakaran, juga berfungsi sebagai tanda bahwa ada sistem yang error atau fault. Alarm Danger berfungsi sebagai peringatan kepada semua orang yang berada didalam gedung bahwa sudah terjadi kebakaran dan sistem akan mengaktifkan media pemadaman dalam 30 detik. Prinsip kerja dari sistem proteksi kebakaran dapat dilihat pada flowchart berikut:

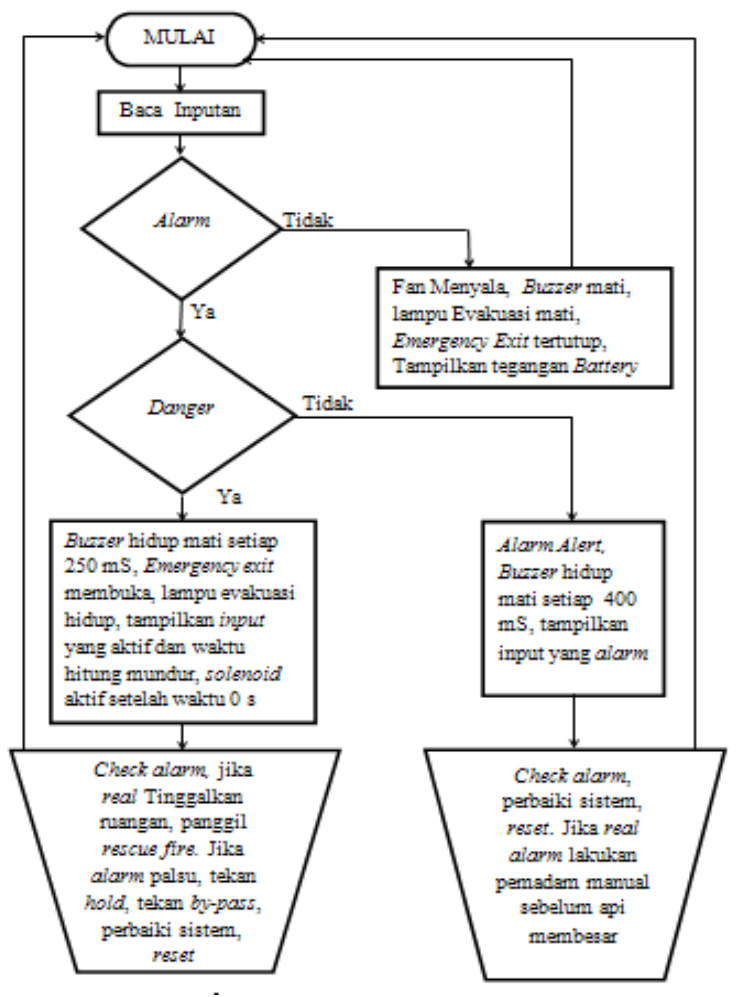

Gambar 1. Flowchart sistem proteksi kebakaran

\section{Hasil dan Pembahasan}

Rancang bangun proteksi kebakaran berfungsi untuk mendeteksi adanya bahaya kebakaran dengan membaca adanya asap atau panas. Sensor smoke atau heat dipasang dua buah dengan prinsip LOGIC AND dimana sensor harus aktif keduanya untuk menghindari alarm palsu. Apabila hanya satu saja yang aktif sistem hanya memberikan alarm, apabila kedua sensor aktif sistem akan memberikan sinyal evakuasi dan setelah 30 detik proteksi pemadaman aktif. 


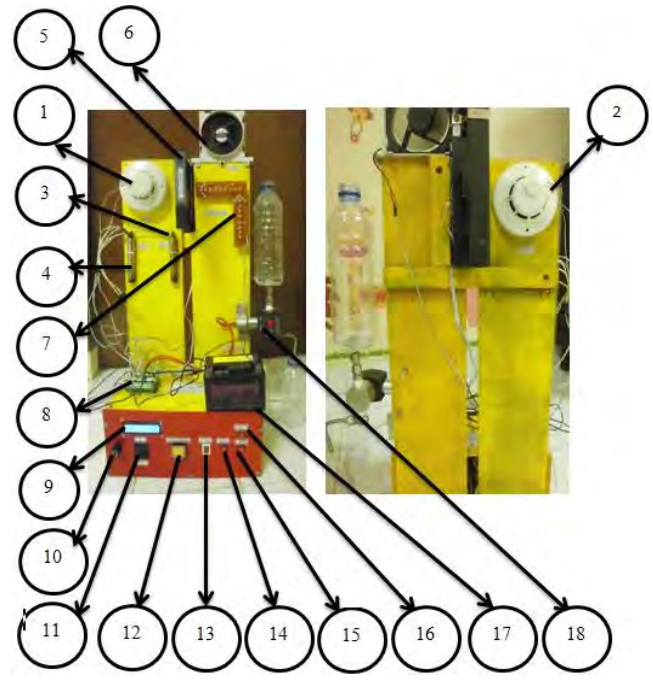

Gambar 2. Rancang Bangun Sistem Proteksi Kebakaran

Keterangan Gambar:

1) Smoke Detector 1

2) Smoke Detector 2

3) Heat Detector 1

4) Heat Detector 2

5) Emergency Exit

6) Fan

7) Lampu Evakuasi

8) Terminal Kabel

9) Display $L C D$

10) Fuse

11) Tombol Power

12) Manual Switch

13) Bypass Switch

14) Reset Switch

15) Mute Switch

16) Hold Switch

17) Battery Back-up

18) Solenoid Valve

Sistem menjadi lebih safety dengan ditambahkan beberapa fitur seperti manual switch, bypass switch, hold switch, dan mute switch. Fungsi Manual Switch adalah apabila terjadi bahaya kebakaran, tetapi sistem tidak memberikan proteksi atau alarm, dengan menekan tombol ini sistem akan memberikan alarm, jalur evakuasi, serta proteksi pemadaman. Perawatan atau perbaikan pada sistem perlu dilakukan, saat melakukan perawatan bypass switch perlu diaktifkan, sehingga saat melakukan perawatan sistem tidak mengaktifkan media pemadam api. Mute switch berfungsi untuk membuat alarm posisi diam. Alarm palsu bisa saja terjadi pada sistem ini, jika sistem sudah memberikan alarm dan evakuasi, waktu untuk mengaktifkan media pemadaman api bisa diundur dengan menekan hold switch, sehingga waktu akan kembali ke 30 detik.

\subsection{Uji Coba Sistem Sistem}

Pengujian merupakan faktor penting untuk mengetahui fungsi dari alat pemadam kebakaran ini. Pada alat pemadam kebakaran pengujian alarm dilakukan sebanyak 729. Kondisi normal dari sistem proteksi ini dapat dilihat dari tampilan LCD, kipas dipastikan berputar seperti, Pintu Emergency Exit dipastikan masih tertutup, Lampu evakuasi dipastikan tidak menyala, dan air pada output solenoid valve dipastikan tidak mengalir.

Pengujian alarm alertdengan diberi inputan (asap atau panas pada sensor, manual switch, dan bypass switch diaktifkan atau dikondisikan fault, memutus aliran listrik $220 \mathrm{VAC}$ (Battery), maka buzzerdipastikan hidup mati setiap $400 \mathrm{~ms}$, dipastikan LCD setiap $400 \mathrm{~ms}$ menampilkan pesan alarm bergantian, jika tombol mute ditekan maka buzzerdipastikan selalu mati, fandipastikan tetap menyala, lampu evakuasi dipastikan tidak menyala, pintu Emergency Exitdipastikan tetap menutup.

Pengujian alarm danger dengan diberi inputan (asap, panas, atau manual switch diaktifkan), maka buzzer dipastikan hidup mati setiap $250 \mathrm{~ms}$, jika tombol mute ditekan maka buzzer akan selalu mati, Fan dipastikan berhenti berputar, Lampu evakuasi dipastikan menyala, Pintu Emergency Exit dipastikan membuka, LCD dipastikan menampilkan pesan alarm serta waktu hitung mundur, untuk pengetesan HOLDrelease, tombol $H O L D$ ditekan maka waktu hitung mundur kembali ke 30 detik, setelah waktu hitung mundur mencapai 0 detik Output Solenoid Valve dipastikan mengeluarkan air dan dipastikan LCD menampilkan pesan alarm. Jika alarm sudah normal, tombol resetditekan, sistem dipastikan kembali normal. 


\section{Kesimpulan}

Berdasarkan penelitian dan pembahasan tentang sistem proteksi kebakaran menggunakan smoke dan heat detector berbasis mikrokontroler ATmega 32, maka dapat diambil kesimpulan sebagai berikut:

1. Sistem proteksi kebakaran mampu mendeteksi adanya bahaya kebakaran dan memberikan peringatan atau alarm kesemua orang yang berada didalam gedung untuk segera mengambil tindakan, mampu melindungi gedung dan peralatan yang ada didalamnya karena memberikan proteksi berupa pemadaman api sebelum membesar.

2. Sistem deteksi dan proteksi kebakaran telah berhasil dirancang dan dibuat dengan menggunakan inputan smoke, heat detector, dan switch. Bagian kontrol sistem deteksi dan proteksi kebakaran menggunakan mikrokontroler ATmega32, sedangkan untuk bagian output menggunakan buzzer, Solenoid valve, LED, $L C D$, motor $D C$.

3. Saran-saran yang berguna bagi pengembangan selanjutnya, diantaranya adalah 1) Perlu ditambahkan SMS Gateway atau jaringan internet yang terhubung ke Rescue Fire, 2) Sebaiknya ditambahkan dengan gas detector, flamedetector yang mendeteksi cahaya api, spilldetector. 3) Agar lebih safety perlu ditambahkan sebuah sensor yang mendeteksi adanya orang atau benda yang berada dipintu emergency saat sistem dinormalkan kembali.

\section{Daftar Pustaka}

[1] Badan Nasional Penanggulangan Bencana. 2014. Data kebakaran pemukiman. http://geospasial.bnpb.go.id. Tanggal akses 6 Oktober 2014.

[2] Arifianto, B. 2014.Mikrokontroller for forBeginer. http://www.maxtron.com.Tanggal akses 11 Mei 2014.

[3] Farid. 2013. Fungsi,Jenis-Jenis dan Pengertian Induktor. http://fartkj3.blogspot.com. Tanggal akses 11 Mei 2014.

[4] Mirza. 2010. Jenis-Jenis Detector FireAlarm. http://www.tanyaalarm.com.Tanggal akses 11 Mei 2014.

[5] Turahyo, 2013.Modul pembelajaran Sistem Mikrokontroller, Teknik Elektro STITEK.Bontang.

[6] Kitoma.2014. Cara Kerja Solenoid Valve. http://www.kitomaindonesia.com.Tanggal akses 15 Mei 2014.

[7] Purnama, A. 201.LED (Light Emitting Diode).http://elektronikadasar.web.id.Tanggal akses 15 Mei 2014. 